\title{
Elements influencing Human Resources fulfillment: A Comparative Study of the impact of interior and outside work inspiration on employment fulfillment in Retail division in Malaysia
}

\author{
${ }^{1}$ Abul Kalam Azad, ${ }^{2}$ MD Keramat Ali $\&{ }^{3}$ Mohamad Sahidullah \\ ${ }^{1}$ Ph.D Scholar, PGC of Limkokwing University of Creative Technology, Malaysia \\ ${ }^{2} \mathrm{Ph}$.D Scholar, University of Macerate, Italy \\ ${ }^{3}$ Ph.D Scholar, PGC of Limkokwing University of Creative Technology, Malaysia
}

\begin{abstract}
The investigation uncovered that the Malaysian retail segment has rehearsed dynamic changes over the most recent couple of decades with the presence of new retail arrangements, for example, hypermarkets, vast scale grocery stores, retail shops, show focus, brand shops, chain shop and comfort stores. Thus, it has included the manner in which representatives work and their guarantee to their association. In this manner, it is vital for retailers to know the explanations behind the representative inspiration, work fulfillment and hierarchical duty outside and inside. The reason for this investigation is to analyze the different Motivating and De-inspiring variables, controlling the activity fulfillment and to distinguish the connection between representative inspiration, work fulfillment and authoritative responsibility. Further to relate to the blow of statistic factors on Retail representative's inspiration, work fulfillment and authoritative duty. The examination concludes that propelling factors in particular great compensation, fiscal benefit, non-money related benefit, the perspective of advancement, work preparing and advance and testing errand were the factors that is only in charge of by and large inspiration and fulfillment of representatives in the present place of employment. It has additionally been additionally presumed that factors in charge of hierarchical responsibility are great pay, non-money related benefit, poor association with equivalents, profession advancement, work preparing and advance, testing assignment, affirmation from friends and best administration. Poor association with partners and Working extended periods, Lack of acknowledgment from best administration, Disrespect from best administration, Poor Working Conditions, Inadequate administrative skill of best administration. In this way, inspiration is a mental characteristic prompting hierarchical responsibility. This exploration underpins the proclaimed view and checked the hypothesis that there be available a solid connection between inspiration, work fulfillment and hierarchical duty.
\end{abstract}

Key Words: Human Resources, Shops, Motivating, Work Fulfillment, Employment, Responsibility.

\section{INTRODUCTION}

The reason for this examination is to focus on the effect of interior and outer work motivation on occupation fulfillment among representatives in the retail segment of Malaysia. In the rhythmic movement area, an audit of the organization business and the examination establishment are included. Besides, the criticalness of the examination is tended to. The result of the talk is to choose the convergence of the examination that prompts the request and focuses of the investigation. As necessities be, a hypothetical structure is in like manner assessed.

\subsection{Background of the examination}

In any activity, work fulfillment is outside for representatives to be roused to proceed in the activity. In present day world experts can never play out their commitments legitimately until the moment that they have satisfied to make each vital stride. Without satisfying their necessities and needs laborers can't create their best yield, for suitable fulfillment in occupation agent need real motivation and distinctive workplaces. There are various perspectives to work fulfillment, dependent upon what each one of a kind individual feels is imperative. From numerous perspectives, the word 'compensate' alone can mean differing issues to different people, and in this specific examination the effect of outer and inward work motivation on occupation fulfillment among representatives in retail part in Malaysia will be investigated in more prominent subtleties.

Motivation is a champion among the most basic keys to advance. Without motivation specialist can't give his or her best yield. The achievement of any affiliation depends upon delegate's fulfillment. Boss have the obligation to make a proper and dynamic air, where they can work uninhibitedly with no faltering. 
Malaysia is a country that in the ongoing three decades have enhanced its fiscal condition in a well ordered way. The nation is a characteristic the travel industry fascination and pulls in nearly all the time colossal quantities of global vacationers. Likewise, the number of inhabitants in Malaysia makes colossal interest for retail segment. In the present situation, extremely forceful retail grandstand is there which is wide verification of affiliations paying little notice to the size, mechanical advances, publicize focus, are standing up to upkeep challenges (Ramlall, 2011). Fitz-end (2014) communicated that the typical association loses around \$1 million with every ten authoritative and master workers who leave the affiliation joined with the prompt and atypical costs; the total expense of an acquitted agent's turnover is something like one year's remuneration and focal points. Ahmad (2014) contended that purposeful turnover is an important issue by virtue of the delegate's activity disappointment for retail area in some Asian countries, for instance, Malaysia, Thailand, Taiwan, etc. Occupation bobbing has ended up being so extraordinary in these Asian countries that it has, somewhat, transform into a culture. In the present business condition, the future has a spot with those administrators who can best direct change. To manage change affiliations must have representatives who are propelled and centered around the solicitations of quick change and everything considered animated and gave workers are the wellspring of advantage (Dressler, 2010). Prodded and satisfied representatives are essential to the accomplishment of affiliations, especially in the organization organizations (Walkup 2011). Healthy (2012) indicated that perfect staffing has been seemed to affect clearly on staff affirmation and employment fulfillment, which in this way is traded to the customers' contribution and that is the fundamental issue. People in like manner land frustrated with their positions just in light of the way that their employments don't have meaning any more. In this way, giving work that is critical shows up the principle way out for bosses to satisfy their representatives in their organization limit, have a fundamental impact in embellishment motivation, obligation and tendencies of the workforce in an affiliation. They give direction focus, which mean inspiration to the people who work for them. As retail outfit shop of an affiliation, managers need to confer to representatives, how to esteem course of action with customers which is basic for retail area.

\subsection{Problem explanation}

The magnificence of any affiliation depends upon the sum they are prepared to take new difficulties and to get industrious work for get association or establishment goals. It is simply possible when delegate are all around satisfied and they believe they are the bit of the association. Starting late, there are a noteworthy number of issues in Malaysia's organization of human resource in the retail segment. As, high worker turnover, strong occupation weakness and high work costs are harming the nation's notoriety. These issues are explicitly or roundabout related with dimension of representatives fulfillment in the retail business. Thus, with a particular ultimate objective to handle these issues, there is a need to make sense of what should be conceivable to upgrade the fulfillment of representatives in the organization business which fills in as the essential motivation for this examination to choose the segments (outside and inward motivation) that sway the workers work fulfillment in the retail business in Malaysia. In perspective of the need to upgrade the activity fulfillment of the representatives, there is a need to dismember the parts (outer and inward persuasive factors) in the retail segment. The relationship among motivation and employment fulfillment can be seen essentially as: motivation can be explained as what individuals attempt to achieve better. In any case, only one out of every odd individual gets prodded by the indistinct parts. Someone may get impelled or satisfied by achieving higher master and commitment while some other individual basically needs versatility in the work schedule, or someone may be induced by a sentiment of accomplishment. Motivation solely impacts people when they are set up for it and when it is associated in the best way sensible for them. That is, the time when it supports the necessities of the person to be pushed. Still the motivation won't have any effect on individuals in case they can't play out an endeavor or if they are not set up to play out explicit assignments. Consequently, this paper is intended to consider every single one of those representatives who are related with retail part industry that describes outer and inner work motivation factors and how these motivation factors impact the activity fulfillment among representatives in the Malaysian retail division industry. In any case, there are two or three focuses on the coordinating effect of organization between motivation factors and occupation fulfillment, especially in the retail area industry of Malaysia. Does expert have any association between outside/inside motivation and employment fulfillment? This paper is wanted to consider how organization impacts motivation and employment fulfillment as a coordinating part in retail division in Malaysia.

\subsection{Centrality of the investigation}

This specific examination could be of importance to pioneers to research the outward and innate motivation that influence work fulfillment among its representatives inside the organization condition. It will be useful to understand and to perceive inalienable and incidental goals as each ha a section in choosing the dimensions of motivation in different work environment. In particular, chiefs could be better partners of their staff in case they can perceive individuals who are even more evidently prodded like giving a test or enabling achievement, for instance, obligation.

\subsection{Scope of the investigation}


The degree of the present examination is obliged to evaluate the working environment and employment fulfillment of the pros of the retail shop in Malaysia by concentrating just on retail part in Malaysia. Data will be assembled through dispersion of 400 (four hundred) polls in and around Kuala Lumpur, Penang and Johor Bauru.

\section{5 constraint of the examination}

In any examination or proposition there has some limitation. The accompanying variables will be a portion of the confinements of the examination:

1 Could not contribute satisfactory vitality, which was required for the all-around examination.

2 The examiner generally limited to simply the 400 polls.

3 The examination may not be illustrative for the all workers who simply work in retail shop.

4 Corrective measures for recognized issues are not covered in it in view of nonappearance of experience.

5 Due to time limitation not having the capacity to cover entire of Malaysia.

\subsection{Definition of the factors}

Suggesting past research, operational implications of the elements in this examination are given:

\subsubsection{Outside work inspiration:}

Outside work motivation is the motivation to achieve a remark without question that some outer target is accomplished or that some outer constrained impediment is met. (Lindenbery, 2001; Hennessey and Amabile, 2005; Sansone and Harackiewicz,2010; Ryan and Deci,2010).

\subsubsection{Inside work inspiration:}

Inside work motivation is the motivation to do or act to one's most noteworthy preferred standpoint or fundamentally for the satisfaction with respect to the activity itself. (Herzberg, 2015; Deci, 2013).

\subsubsection{Employment fulfillment:}

Employment fulfillment is exactly how people feel about their occupations and different parts of their occupations. (Spector, 2010 Kinicki and Kreitner, 2014; Sharma and Jyoti, 2016).

\subsection{Research Destinations}

1. To find the current circumstance of the representatives who work in the retail area in Malaysia and to fathom the effect of measurement factors on retail representatives in outside work motivation.

2 .To recognize the inward work motivation and occupation fulfillment of representatives working in different Malaysian retail part.

3. Accomplishing a higher worker work fulfillment has reliably been one of the essential objectives of every affiliation which expect a crucial part that sway work fulfillment among the representatives in the Malaysian retail division.

4. To discover increasingly about approaches to expand the staff degree of consistency in retail part in Malaysia.

5 To set up an instrument with the goal that further research is done to extend representative fulfillment as a standout amongst the best in the South East Asian area and depict the picture in the outside world.

\subsection{Research questions}

1. What is the effect of outside work motivation in retail segment?

2. What is the effect of inward work motivation in retail segment? 
3. What are the parts that choose the fulfillment dimension of workers?

4. How to draw in representatives more in the retail division in Malaysia?

5. What can be the approaches to enhance the picture of retail area in Malaysia with the goal that representatives are held over a significant lot of time?

\subsection{Theoretical Framework}

As showed in the beneath referenced figure, the determined structure of the two variables are interrelated and it is very far-fetched to confine them. Subordinate elements are factors that expert will measure in order to develop change or effect made on them. From the connected edge work above, affirmation is the most basic and incredible spurring powers for upgraded execution. According to (Ricks et al., 1995) seeing self-induced, independently directed and truly gainful individual will enable and support the continuation and progression of the above features in the representatives which will resultant set for a case for others to take after. Regardless, affirmation is the vitality about execution by the relationship of a showing done by the associate. Affirmation has two fundamental goals: directly off the bat is to engage the workers or gathering to go over or continue with the lead and furthermore is to encourage distinctive representatives to do in like manner. Recognition, anyway should be given astutely it must be veritable related to certified achievements. Cash related; rewards, especially achievement rewards allowed immediately after the event, are clearly pictures of affirmation to which considerable points of interest, and this is a basic course in which regularly bracing strategies of budgetary and non-money related prizes can work. Most of the gathering affirmation structures fall into celebrating progressive targets routinely an event, proposed to perceive the productive performed of basic association goals. Affirmation, either easygoing (oral) or formal (created remarks and events) has been the best way to deal with strengthen required for execution inside an affiliation. In any case, when affirmation is acting in disconnection of compensation and esteem remunerate its generally loses a lot of its charm. Boost in compensation as showed from the figure above figure is moreover a factor influencing delegate motivation. When an agent pay has been extended, life's ended up being fundamentally less requesting as in you will have the ability to accomplish with the increase. Boost in compensation gives representatives a sentiment of being seen for his/her effort in this way he/she will be therefore reflecting that in his or her execution. Headway is constantly a dream of an agent in any affiliation. A couple of workers prevail in fulfillment of their dream however the others don't the reason for this accomplishment or dissatisfaction is their execution. Heads of affiliation, should propel their representative's audits on the reason of their execution making the right evaluation. This elite gives them fulfillment yet also invigorate a sound contention among the workers benefitting the affiliation and making it perceived among contenders (Royal, et al, 2014). Employer stability. If a delegate is sure of his/her present employment, he will have inside harmony that will constrain you from considering and you will have the ability to develop more energy for the execution of the activity Coordinated effort is used across over a wide scope of relationship with a particular ultimate objective to grow execution, laborer solidarity and companions culture. Participation is basic as a result of the basic reasoning joint effort grabbed from different identities wearing down an answer. By using participation, partners pool their total contemplations together to create wonderful musings for overseeing issues. Nevertheless, cooperation is the establishment of convincing correspondence inside an association. Right when representatives fill in as individuals or selfgoverning on endeavors, they may not expeditiously share learning or new information. Joint effort progresses exchange between representatives as for the activity that should be done, conceivably shielding workers from working in converse ways. Association is in like manner an essential symptom of cooperation inside an association. This association could be the outcome of extended science, trust or both from accepting a shot at endeavors as a gathering.

Furthermore, when workers coordinate as a gathering inside an association, every agent gains from one another. This learning isn't limited to the individual experiences of teammates; workers from different divisions may take in information from one another as for the repressions and potential results of those workplaces.

\section{LITERATURE REVIEW}

\subsection{Introduction}

This part gives a layout of contemporary research on the effect of outer and inner work motivation on occupation fulfillment among representatives in retail area in Malaysia. We start by perceiving the central premises, discusses, and unanswered request related to five focus speculative perspectives on work motivation: expectation theory, esteem theory, target setting theory, work diagram, and confidence speculation. We by then discussion around four current subjects and new headings: total motivation and dealing with, passing stream, imaginativeness, and the effects of prizes. Employment fulfillment is described as a man's evaluation of his or her activity and work setting. It is a degree to which one feels earnestly or antagonistically about the regular just as outward parts of one's activity. In less mind boggling words, it is about how workers feel about various parts of the activity. Since 
occupation includes distinctive extents, work fulfillment is habitually conceptualized as a multidimensional form that involves various parts, generally called employment fulfillment angles. Ordinary employment fulfillment highlights fuse partners, appreciation, benefits, work conditions, pay, headway, supervision, and affiliation's techniques or system. Occupation fulfillment is described as a man's appraisal of his or her activity and work setting. It is a degree to which one feels determinedly or oppositely about the common or conceivably outward parts of one's activity. In less demanding words, it is about how representatives feel about various parts of the activity. Since occupation involves diverse extents, work fulfillment is as often as possible conceptualized as a multidimensional build up that contains various segments, consistently called employment fulfillment viewpoints. Typical occupation fulfillment highlights consolidate partners, appreciation, benefits, work conditions, pay, headway, supervision, and affiliation's methodologies or philosophy.

\subsection{INNER WORK MOTIVATION}

Lufthansa (2012), communicated motivation as an enthusiastic, driving component in direct. It starts the representatives to complete their occupations and achieve recognized targets. A technique for enabling people is using a primary force in them, which prompts fulfillment and obligation in their employments. The viewpoints of the laborer about inside work motivation and duty also depend upon various leveled lead and execution of human resource organization. Of course, work obligation depends upon the points of view of delegate about the whole affiliation. Notwithstanding the way that there was a critical association among motivation and employment fulfillment. At the point when all is said in done, it can't be disregarded that pushed representatives feel increasingly satisfied and dependable and don't review to leave or change their workplace and besides exhibit their devotion towards work. According to Bauer and Bender (2010), motivation is separated into three territories. The underlying fragment suggests the vitality of impelling or the inactive essentialness inside a man. The second part implies the kind of essential initiative and heading in embellishment their lead. The third part suggests the dimension of social consistency for meeting their targets.

Excavator et al. (2011) communicated that, motivation contains necessities, drives, and inspirations and their correspondences. Of course, organization experts and boss trust that a various leveled target depends upon the workers' devotion Motivation ought to be an average factor, inciting a predominant execution and encircling practices and it tends to be in the hands of every head. It should be seen that motivation can be in inward o outside structures. Inward motivation is the drive for just completing a movement. For example, work interest, advancement, affirmation, and achievement.

\subsection{Outside Work Motivation}

Fit as a fiddle, agent's exercises and concerns are roused by outside spurring powers like reward, information, and control Linz (2014). Cornelian (2013), states that opportunity and social relations in the work put braces motivation. Carter et al. (2011) communicated the three factors affecting motivation consolidate information, reward, and individual segments. He in like manner communicates that representatives ought to influenced and invigorated by giving some unprecedented settlement, coincidental points of interest suggesting their incredible execution and specific aptitudes, this will grow the activity duty of the workers. Diverse portions in the affiliation can be viewed as the cash related structure of an affiliation. Dull hued and Sheppard (2012) believe that money is the most enabling framework for representatives in achieving higher productivity. It prompts conveying feelings like prosperity, control, wonder, societal position, accomplishing targets and achievements. The huge development by totally fitting in with their business system through a particularly balanced reward and affirmation programs for supervisors.

\subsubsection{Dimension Of Job Satisfaction}

In this report I chose the effect of agent reinforcing on occupation fulfillment. To fill this need, fortifying is considered as two estimations, for example conduct and mental and the effect of specialist reinforcing on the dimension of occupation fulfillment was examined by pondering these two estimations with everything taken into account and autonomously. The revelations suggest that the best points of view related to work fulfillment are relations with the partners and physical conditions, while the most negative perspective is the compensation issue, for example uncalled for portion.

The activity fulfillment perspective has gotten the most thought consistently and starting late the worldwide legitimate duty has created out as being basic to fathom and envision various leveled lead. Legitimate obligation is considered to give effective responses or airs which interface or associate a laborer to the affiliation and as a perspective, various leveled obligation is often portrayed as a ground-breaking inclination to hold a person from a particular affiliation, a preparation to apply strange measures of effort in light of a legitimate concern for the affiliation and a reasonable trust in and affirmation of the characteristics and targets of the affiliation. 


\subsection{Connection}

An especially regulated affiliation usually watches a typical expert as the root wellspring of significant worth and gainfulness grabs and such affiliations don't scan for capital hypothesis, yet to representatives, as the key wellspring of progress. An affiliation is feasible to the amount it achieves its goals and an effective affiliation will guarantee that there is a spirit of support between motivation, fulfillment and a sentiment of obligation inside the hover of its effect. Remembering the true objective to make workers satisfied and concentrated on their occupations in retail area, there is a prerequisite for strong and incredible motivation at the diverse dimensions of the affiliation.

Lathan's (2014) expressed that motivation is the technique that blends, enables, arranges, and oversees lead and execution and it is the route toward enlivening individual to movement and to achieve a pined for task. One technique for energizing representatives is to use amazing motivation, which makes them more joyful with their activity and concentrated on their occupations. Money isn't the principle motivation and there are diverse impulses which can similarly fill in as aides. While work fulfillment and obligation have been the purpose of numerous examinations, anyway the present examination presents new information and another perspective, delineating about motivation, work fulfillment and obligation of retail heads with respect to retail part representatives of Malaysia.

\subsection{Research Gap}

A reasonable affiliation will reliably propel a sentiment of motivation, fulfillment and obligation among its representatives. The importance and centrality of the possibility of definitive duty to the extent inciting profitable various leveled and charming outcomes, for instance, extended effectiveness, decreasing non-appearance and turnover, has been documented by numerous examinations. One way to deal with location issues of specialist moving out of an affiliation is to grasp the motivation level and occupation fulfillment of workers. Affiliations routinely endeavor to bestow obligation in their workers to achieve security and lessen delegate turnover. It is commonly believed that given representatives will in like manner work more earnestly and presumably "go the extra mile" to achieve progressive targets.

Research has dependably shown that commitment does unquestionably add to a diminishing in laborer turnover. Influenced representatives are required in our dependably changing workplaces and impelled workers to assist relationship with surviving. Awakened representatives are progressively gainful and will be incredible for which managers need to grasp what moves workers inside the structure of the parts they perform and package of studies are immediate obligation, fulfillment and motivation yet not a lot of examinations are there on retail area associating these three creates. So it is major to coordinate an examination on motivation and employment fulfillment in the retail business and besides to recognize the fundamental impelling elements which impacts work fulfillment which will finally help the Human Resource boss with holding the particularly prepared workforce. The review of related composition on Motivation and Job fulfillment has helped the specialist to perceive the opening and has given a comprehension to the course of the energy look at consider.

Occupation fulfillment is an inevitable concern, a test for present day affiliations. Today people search for affiliations where they can have a voice and be seen for their own responsibility in a solid working environment. Their brief boss enormously influences their regard structure fit with the affiliation and their dimension of employment fulfillment

Right when there is nonattendance of motivation, you either get no results, or simply normal ones, however, when there is motivation, you achieve increasingly vital and better results and achievements. Investigate an understudy who needs motivation and who hardly ponders, to an understudy who is significantly vivacious, and who commits various hours to his examinations. Each understudy will get totally exceptional assessments .Lack of motivation suggests nonappearance of fervor, get-up-and-go and yearning, while the responsibility for means that amazing urge, imperativeness and vitality, and the capacity to take the necessary steps to achieve what one sets out to do. A convinced individual is an increasingly blissful individual, progressively vivacious, and sees the positive last item in his or her mind

\section{RESEARCH METHODOLOGY}

\subsection{INTRODUCTION}

This part looks at the methodology that is used as a piece of this examination. The essential territory delineates the methods for research diagram. The second part takes after by data gathering technique. The third part portrays test profile, test measure and analyzing technique. The fourth zones illustrate estimation and instrument of variable. The fifth territories drove ask about surveys. The sixth parts trial of variable organization. At long last seventh territories data examination and research framework. 
This investigation consider was coordinated in light of the logic. This system expect a basic part in realizing this investigation look at moreover. The inconspicuous components of the procedure are cleared up in detail in this area.

\subsection{Research Design}

Both basic and helper data are used with the true objective of the examination. The examination is for the most part in perspective of basic data. The basic data will be accumulated through individual gathering of the workers retail shop. In any case, the data couldn't be assembled from simply fundamental sources, would be accumulated through helper sources. Unmistakable sorts of data and their sources are discussed under the going with heads.

\subsection{Essential DATA}

The essential information will be accumulated through individual gathering with the master and workers used by sorted out overview. To accumulate the essential information there three courses of action of meeting designs, extraordinarily orchestrated in the light of the goals of the examination. The assembled information will be as such arranged, masterminded and dismembered with the true objective of the examination. The assembled will be dealt with, sorted out and separated in the real way.

\subsection{Auxiliary DATA}

The information couldn't be assembled from essential sources have been gained through discretionary sources. The discretionary sources join books, journals, yearly report and unpublished research works.

$1 \quad$ By Sample information gathering

2 Data gathering from outside source

3 Data gathering from inner source

4

Data examination

Research procedure is fathomed to be a conscious technique for dealing with the investigation issues essential rationale behind the methodology. In the present examination, method is taken to exhibit the central measures and techniques or dealing with and the structures or demand framework provoking realization of the examination. This game plans with various methodological issues relating to the examination like profile of the example unit, test size of the respondents, wellsprings of information and examination of information used as a piece of the examination. Research arrangement suggests the methodology and assorted sections that planned with the examination and help us to find the issue reasonably and ensure the motivate affirmation to engage us to speculatively deal with the issue. However, Quantitative research is tied in with moving toward people for their decisions structurally so we can convey hard substances and estimations to coordinate. To get strong authentic results, it's basic to review people in really gigantic numbers and to guarantee they are an operator trial of our goal showcase. Here we use ordinary methodology of research plan key and use cases.

\subsection{POPULATION}

The target masses for this examination described to consolidate the delegate of retail division in Malaysia, while the open people is the specialist of retail segment in Kuala Lumpur. The delegate of retail part were seen as appropriate as masses of the examination region in light of the way that, as communicated in the examination. Most of them have had a significant extended period of time of business, they are in the best position to equip the specialist with the information expected to answer the examination question of this examination. For a couple of examinations, the masses may be adequately little to warrant the thought of all of them in the examination. Regardless, an examination may include a broad people which can't all be mulled over. That piece of the masses that is considered is known as an example of the people.

\subsection{Test SIZE}

Examining is method of picking specific units (for example people, establishment) from a tremendous masses so that by concentrate the model scientists may tolerably whole up their result back to the masses from which they were picked. It is major that the investigation obviously portray the goal masses. It's not sensible to assemble information from whole people. That fore research use a precedent as opposed to it (failed,2005), in this examination the example was assembled especially from positions , as demonstrated by the model measure choosing table, displayed by Morgan and Krejcice, 32 should be test gauge for 35 masses. 


\subsection{SAMPLING TECHNIQUE}

There are four classes for analyzing methodology in the social and conduct sciences which are Probability, Purposive, and Conveniences testing, the reviewing technique followed in this examination is a specific; purposive framework, this kind of testing incorporates the plan of specific elements which might be basic and feasible for the investigation region, the example assurance relies upon excitement of study organization of relationship with grouped workforce, focusing on complexities among sexual introduction, culture and nationality, the administering stuff and the regulatory party in Malaysia transform into a picked target, in light of the way that it's less difficult to increment exact information and information outline affiliation that are close to, correspondence was up close and personal to assemble the information, its contains the required guide to be tended to from either the instructors and troughs, who are starting from deferent nationality and are from different genders. Testing is an imperative point of view in pass on our any kind of research consider, if there is some oversight in information amassing, it can affect the eventual outcome of study. There are two sorts of information gatherings:

\section{SUBJECTIVE AND QUANTITATIVE:}

A subjective and quantitative study of the work motivation work fulfillment and occupation execution is given. The subjective and quantitative overview is formed around 7 models that portray past research on the work motivation between employment fulfillment and occupation execution. But a couple of models have gotten more help than have others, investigate has not given complete assertion or disconfirmation of any model, generally by virtue of a nonattendance of ingestion and mix in the composition. Research focused on testing these models softened away after meta-examinations of the activity fulfillment work execution. In light of obstacles in these prior examinations and the contortion of their revelations, another meta-examination was driven on 312 precedents with a consolidated $\mathrm{N}$ of 54.417. The mean certifiable connection between's general occupation fulfillment and employment execution was

Assessed be .30. In light of these results and the subjective study, an inspiration for future research on the fulfillment execution relationship is given. Where's the fundamental giving off on social affair subjective examples and sorted out information gathering gadgets, the out coming results are anything but difficult to join and consider. The second is subjective information gathering system, which has a basic part in affecting the information evaluation through giving accommodating information to understand the strategies behind shut results (leedy and Ormrod, 2001) in this examination, a survey audit was driven and appropriated among the concentrated on responds to assemble essential information, and the accumulated information record surpass desires database to avoid information missing oversight. Study has a couple of inclinations, it can send to a wide number of people and time and money. Responds are increasingly certifiable and open in their response to the surveys, it might be a result of how their response are undisclosed. On the other hand, there was number of downside. Numerous people who get overviews don't return and the people who do won't not respond the basically picked test.

\subsection{MEASUREMENT AND INSTRUMENT OF VARIABLE}

\subsubsection{MEASUREMENT OF INTERNAL MOTIVATION:}

In this examination, Independent variables impact specialist economics and advantage. Delegate Socioeconomics consolidate age, occupation, family status, pay level and sexual introduction. These parts impact what an agent needs, which impacts advantage and finally benefits. A couple of variables have a circuitous relationship with organization and demand. For example, it depends after advancing. Budgetary variables impact business advantage. The fulfillment of individual agent and expert of representatives of retail division in Malaysia are free factors that impact general business execution. The primary region is penniless elements with 3 questions (Internal Motivation).

\subsubsection{MEASUREMENT OF EXTERNAL MOTIVATION:}

Specialist has picked one DVs explicitly, organization parts and control in managing not too bad assortment, five point-liker scale to check to measure the dependent variable, the used scale is following like decidedly agree, agree, unbiased, go amiss, solidly contradict, which infers a size of 1-5 region. In the investigation survey two things (The master has figured out how to adapt the staff with the equal open entryways methodology, organization of the strip mall shows a commitment to address the issues of representatives with insufficiencies) are used for DV. There are 4 inquiries as for the destitute elements consolidated into section two (External Motivation). 


\subsubsection{MEASUREMENT OF JOB SATISFACTION:}

Research design can overpower for a wide scope of analysts. At its heart it might be depicted as a formalized methodology toward basic reasoning, considering, and picking up learning and the achievement of research.

Analyst has picked four control factors which are organization, agent, motivation and employment fulfillments.

\subsection{DATA ANALYSIS PROCEDURE:}

A movement of exercises or steps performed on information to check, sort out, change, fuse, and remove information in an appropriate yield shape for coming about use. Methods for planning must be completely recorded to ensure the utility and dependability of the information. Ensuing to social affair new information, using own officially accumulated information, reusing someone others information in conclusion Data Analysis incorporates exercises and methods performed on information that help portray realities, perceive plans, make elucidations and test theories. This fuses information quality affirmation, quantifiable information examination, showing, and interpretation of examination result.

This paper makes different proposition including the usage of a most noteworthy quality dimension coding to consider the common master's codes against. Steadfastness measures should reflect the course in which the documentation information is penniless down with the objective that evaluations can be impacted concerning how much to each factor presented in the results was coded unequivocally. The Yule's Q estimation, in perspective of the odds extent, is endorsed as the resolute quality estimation of choice for straight out information because of the intuition of the measure, its straightforwardness of figuring and its conspicuous genuine nature to the essential initiative of execution analysts. Additionally an estimation of 0.95 or above should be regarded a satisfactory motivator to choose trust in the inspector's ability to put an event into a class reliably.

\section{INTRODUCTION}

Information accumulation is a productive strategy of social event focal point information about need objective from picked test under controlled setting. The gathering and use of similar and related information from different sources using various gadgets, this part demonstrates the information accumulated from the diverse association in Malaysia. The information are accumulated from the diverse association Staff. As demonstrated the essential respondent social events of the survey were the Staff of various association who work in those association long time. The total of twenty customer was met. All could be come to and viably taken through the study. The tables and figures underneath display the measurement profile of these Employee.The alpha coefficient for the four things is .836 , suggesting that the things have respectably high inward consistency. That a reliability coefficient of .70 or higher is seen as "commendable" in most human science investigate conditions. Here $\mathrm{N}$ is proportionate to the 14 number of things, c-bar is the can't avoid being the ordinary between things covariance among the things and v-bar measures up to the typical change. This investigation one can see from this formula that if the extension the amount of things, addition Cronbach's alpha .719. Also, the typical between thing relationships is low, alpha will be low, and alpha will be low. The examination as the ordinary between thing relationship manufactures; Cronbach's alpha additions also holding the amount of things unfaltering.

\subsection{DEMOGRAPHIC ANALYSIS}

sponses were gotten from 20 respondents. The essential respondent social affair of the outline were workers in the retail division of Malaysia distinctive association. All staff could be come to and successfully taken through the review. Ensuing to screening and examination, 14 surveys were destitute down. This that the respondent's rate was $100 \%$. The tables and figures underneath present the measurement.

\section{INTRODUCTION}

This part gives a review of dialog of research on inward and outside work inspiration and occupation fulfillment. We begin by recognizing the focal premises, contentions, and unanswered inquiries identified with five center hypothetical points of view on work inspiration and occupation fulfillment: hope hypothesis, value hypothesis, objective setting hypothesis, work structure, and self-assurance hypothesis. We at that point examine four current themes and new headings: aggregate inspiration and arranging, transient elements, innovativeness, and the impacts of remunerations.

\subsection{Discussions:}

5.2.1 Hypothesis of Internal Motivation 
Ho 1: Adoption of extraneous prizes does not have critical relationship on the worker's execution.

Ho 2: Adoption of inborn reward does not have noteworthy relationship on the worker's execution.

Ho 3: Adoption of persuasive instruments does not have critical impact on authoritative profitability.

\subsubsection{Hypothesis of External Motivation:}

Speculation 1: External inspiration has positive effect on authoritative advancement.

Invalid Hypothesis: External inspiration has no positive effect on authoritative advancement.

Speculation 2: Extrinsic inspiration has positive effect on hierarchical advancement.

Invalid Hypothesis: Extrinsic inspiration has no positive effect on hierarchical advancement.

\subsection{Limitation of Research:}

It imperative to know that no mach indisputable research has been done in the administration job, work inspiration, hob fulfillment, taking care of assorted variety, in a few circumstances the cited hypothesis could be more important than in different circumstances, anyway this ought not be conceder as the reality before leading progressively definitive research, what's more the exploration may acknowledgment limit issue and little example estimate, there are other autonomous factors, which are excluded in this investigation were constrained just to on KWC (Kenanga Wholesale City), Malaysia.

\subsection{Recommendation:}

The point of this examination was to get further information and comprehension with respect to the administration job, inside and outside work inspiration, work fulfillment, taking care of assorted variety and decide the subsequent impacts from specific factors upon this job, past hypotheses has been led from which this exploration questions were framed. This examination is consider to be graphic, instructive and illustrative, since analyst could portray the out coming outcomes from connection among reliant and free factors and what impact they will convey to the shopping center. Amid the examination in this postulation, the exploration has discovered rousing territories would be conceivably to do additionally look into on. Specialist prescribes further examination by: Investigation when is leading to multicultural association. This is identified with overseeing decent variety inside money related foundation. A comparable report is best directed through different contextual investigations. This is progressively desirable over accompanied increasingly legitimate speculation. Leading a comparable regions of research however numerous contextual investigation of shopping center from deferent nations, so as to explore similitudes and respect in their administration of assorted variety within association.

Leading an examination on associations that are focusing on decent variety and whether they think about social assorted variety as upper hands or not. Despite the fact that directing a solitary contextual analysis on a heterogeneous activity place.

\subsection{Conclusion}

To discover the workplace and employment fulfillment of the specialists retail shop. We can utilize distinctive sorts of poll. Based on the survey the present examination secured positive relationship between' position fulfillment and execution of the association. Here different determinants will be utilized to discover the activity fulfillment. The determinants, for example, employer stability, work status, working conditions, limited time opportunity, compensation structure, great connection with colleagues and work in opportunity speaks to the activity fulfillment. Inspiration is a standout amongst the most essential keys to progress. Without inspiration representative can't give his or her best yield. The accomplishment of any association relies upon worker's fulfillment. Supervisors have the duty to make a legitimate and dynamic air, where they can work openly decisively.

\section{REFERENCES}

1. Baird, L.S. (1976) Relationship of Performance of Job Satisfaction in Stimulating and Nonstimulating Jobs. Journal of Applied Psychology, 51, 6, 721-727.

2. Blauner, R. (1967), Alienation and Freedom: The Factory Worker and his Industry. Chicago: University of Chicago press.

3. Brayfield, A. H. and Rothe. H.F. (1951), “An Index of Job Satisfaction.” Journal of Applied Psychology, 35, $307-311$.

2. Ewen,R. B.Smith,P.C., Hulin,C.L. and Locke, E.A., An empirical test of the Herzberg Two 
1. Eysenck, H.J. (1962) Know your Gwn IQ. Harmondsworth: Penguin.

2. Feldman, D.C. and Arnold, H.J. (1982), A Multivariate Analysis of the Determinants of Job Turnover. Journal of Applied Psychology, 75, 3, 350-360. Gruen, Nicholas (2004)

3. Peter S. Rose (2001), Commercial Job Management, $5^{\text {th }}$ Edition, New York: Irwin

4. Rose and Sylvia Conway Hudgins (2003), Job Management \& Financial Services, $5^{\text {th }}$ Edition, New York: McGraw-Hill.

5. Reading Materials on General Employment Department.

6. Reading Materials on Management in job Sector, Malaysia.

7. Decker, Paul. "Data Mining's Hidden Dangers." Job Strategies 74, no. 2 (March-April

8. EmploymentSystem. Board of Governors. Consumer Handbook to Credit Protection Washington:

9. Hosmer, LaRue T. A Venture Capital Primer for Small Business. Washington: U.S. Small Business Administration, Management Assistance, Support Services Section, 1982. Inadomi, Kenneth. "What You Need to Know before You Pull a Employment Report." Retail Today, February 1995, 33.

10. U.S. Federal Trade Commission. "Federal Trade Commission." Washington: U.S. Federal Trade Commission, 1999 U.S. Small Business Administration. The ABC's of Borrowing. Washington: U.S. Small Business Administration, 1989. "What's the Score at FHA?" ABA Job Journal 90, no. 10 (October 1998): 54.

11. S. Rufai, "Efficacy of Job Risk Management on the Performance of Retail Sector in Nigeria A Study of KWC (2006-2010)," Global Journal of Management and Business Research Administration and Management, vol. 13, no. 4, 2013.

12. Asha Singh, International Journal of Marketing, Financial Services \& Management Research, vol. 2, no. $7,2013$.

13. "Special Feature: Job Management," Corporate Family Magazine, July - September 2013.

14. Dr. Josef Christl, Dr. Kurt Pribil, Dr. Heinrich Traumulller, Guidelines on Job Management, 2004.

15. "Job Management," Reference Manual - Spring 2005, 2005.

16. D. V. Swamy, "Basel III: IMplications for Malaysia".

17. Sungai Wang, "Job Management: Guidelines for Commercial"

18. Mr Roger Cole; Federal Reserve Board, "Principles for the Management of Job From Basel Committee on Management Supervision," Washington, D.C., 2000. 14. Jorg Hashagen; Global Head Advisory Financial Services.

19. Arain, Karim: Management von Kreditausfallrisiken. Peter Lang, 2004.

20. Bessis, Joel: Risk Management in Job. 2nd ed. Wiley 2002

21. Cossin, Didier \& Hugues Pirotte: Advanced employee Analysis: Financial Approaches and Mathematical Models to Assess, Price and Manage. Wiley, 2000.

22. Dicken, Andre« Jacques: Kreditwu<rdigkeitspru<fung. 3rd ed. Erich Schmidt, 2003.

23. Eller, Roland \& Walter Gruber \& Markus Reif (Eds.): Handbuch Gesamtbanksteuerung: Integration von Markt-, Kredit- und operationalen Risiken. Scharffer-Poeschel, 2001.

24. Everling, Oliver \& Walburga Sarcher: Rating-Lexikon. VO< B-Service, 2003.

25. Fuser, Karsten: Intelligentes Scoring und Rating: Moderne Verfahren zur Kreditwu<rdigkeitspru<fung. Gabler, 2001.

26. Glantz, Morton: Managing Job Risk: An Introduction to Broad-based Engineering. Academic Press, 2003.

27. Grof, Erika: Risikocontrolling und Kreditwu<rdigkeitspru<fung: risikoorientier tes Bankencontrolling unter Beru<cksichtigung neuerer Bonita`tspru<fungesverfahren. Vienna: Linde, 2002.

28. Grundke, Peter: Modellierung und Bewer tung von Kreditrisiken. Deutscher Universita<ts-Verl. 2003.

29. Grundwald, Egon \& Stephan Grunwald: Bonita<tsanalyse im Firmenkundengescha ft: Handbuch Risikomanagement und Rating. 2nd ed. Scha<ffer-Poeschel, 2001.

30. Gundlach, Matthias \& Frank Lehrbass: CreditRisk+ in the Banking Industry. Springer, 2004.

31. Hertenstein, Karl-Heinz \& Dirk Mu<ller: Risikocontrolling im Kreditgescha<ft als Bestandteil eines ganzheitlichen Risikomanagementkonzeptes. Dt. Sparkassen-Verl., 2002.

32. Hose, Christian: Rating und Kreditzinsen: Chancen fu<r Kunden und Kreditinstitute im Rahmen von Basel II. Deutscher Genossenschafts-Verl. 2002.

33. Kley, Christoph R.: Mittelstands-Rating: externe Credit Ratings und die Finanzierung 